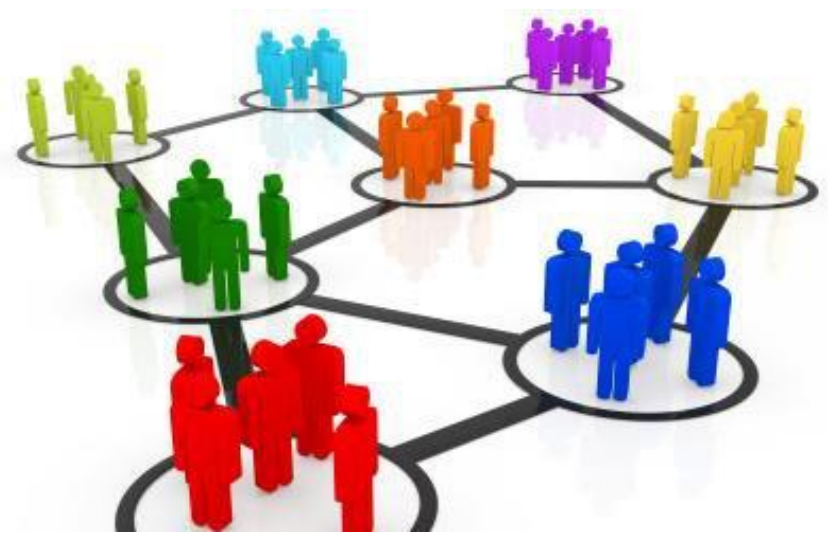

\title{
A ARS (Análise de Redes Sociais): elo entre pesquisa e o ensino
}

ARS (social network analysis): link between research and teaching

Eliane Vitorino de Moura Oliveira ${ }^{1}$

\section{Resumo:}

Com o mapeamento da fala de adolescentes oriundos de um distrito rural da cidade de Londrina, no Paraná, a análise das Redes Sociais de Interação (social networks) é apresentada como um método analítico apropriado para o reconhecimento da realidade linguística dos alunos, ato necessário para a elaboração de materias didáticos que respondam às necessidades atuais. Utilizando o programa Egonet, cuja função é quantificar os contatos pessoais, por meio da identificação de conexões e pontos dentro de uma rede egocêntrica, são apresentados mapas individuais das redes de cada um dos informantes, como um modelo apropriado de reconhecimento das referências linguísticas individuais. Pelo viés da Sociolinguistica, em especial sua vertente Educacional, as discussões com enfoque nos resultados certificam o trabalho com a ARS - Análise de Redes Sociais de Interação - como uma eficiente resposta em busca de caminhos para o eficaz ensino de Língua Portuguesa como língua materna.

Palavras-chave: Análise de Redes Sociais, Português Língua Materna, Ensino.

\begin{abstract}
:
By mapping the speech of adolescents come from a rural district of Londrina, Paraná, shows social networks analysis as an analytical metode appropriate to recognize the linguistic reality of the students, because this recognition is necessary for the development of teaching materials that respond to current needs. Using Egonet Program, whose function is to quantify personals contacts, by identifying connections and points in the egocentric network, this paper presents individuals maps of each informant, a appropriate model for the recognition of individual linguistic references. Under the bias of Sociolinguistica, especially its educational component, discussions on the results certify the work with ARS as an efficient answer to the search for ways to effective teaching of Portuguese language as mother tongue.
\end{abstract}

Keywords: Social Network Analysis; Portuguese mother tongue, Education.

\footnotetext{
11 A autora é Docente na Universidade de São Tomé e Príncipe pelo Programa Leitorado do Governo Brasileiro. E-mail liaoliver13@gmail.com Caixa Postal 789 Distrito de Água Grande - São Tomé - São Tomé e Príncipe.
} 


\section{Introdução}

Falar implica seguir uma ou outra variedade linguística, cuja opção depende do papel social representado pelo usuário da língua em cada uma de suas diversas situações de interação cotidiana. Entretanto, há forças interferindo decisivamente nessa escolha, agindo em favor de uma ou outra forma de falar: as redes de interação.

Vivemos inseridos em redes sociais. Ligamo-nos às pessoas por meio de uma rede invisível e maleável que nos conecta a outras pessoas dos nossos círculos sociais, profissionais e familiares.

Em um trabalho de pesquisa para o Doutoramento, investiguei as relações de 24 adolescentes residentes em um distrito rural da cidade de Londrina, no norte do Paraná, com o intuito de identificar a configuração da fala destes indivíduos para, com isso, propor uma discussão sobre a melhor maneira de trabalhar, na escola, com tal realidade linguística.

Utilizando a ARS - Análise de Redes Sociais como método análitico, foi possível traçar mapas identitários de cada um desses informantes e, a partir deles, estabelecer as conexões e o peso de cada rede para a forma de falar de cada um.

Neste trabalho, apresento tais mapas e discuto os resultados, com a intenção de mostrar o importante papel das redes sociais de interação no ensino de língua portuguesa, uma vez que, conhecendo as redes por que se desenrolam as interações de nossos alunos, podemos não só descrever a variedade efetivamente praticada por cada indivíduo, como também entender sua configuração. E, entendendo sua configuração, será possível estabelecer um ensino voltado para a sua realidade linguística.

\section{A interação por meio das redes}

Conquanto os relacionamentos locais sejam mais frequentes e o conhecimento entre membros de uma mesma comunidade de fala seja mútuo, as pessoas movem-se, aderem a diferentes movimentos, engajam-se a variados empreendimentos, inserem-se em outros grupos, adentram outras sociedades nas quais as relações identitárias têm lugar. Ou seja, há um sensível e tenaz vínculo entre as relações sociais e variação e mudança linguística.

Há três conceitos-chave em Sociolinguística, no âmbito interação-variaçãomudança: comunidades de fala, redes sociais de interação e comunidades de prática, com todos abarcando a interação. Interessa-me, neste trabalho, a noção de Redes Sociais, 
definida por Bortoni-Ricardo (2011) como "um conjunto de vínculos de todos os tipos entre os indivíduos em um grupo".

Inicialmente base de estudos antropológicos, a sistematização desse conjunto de vínculos estabelecidos entre as pessoas - o estudo dos social networks - chega à Sociolinguística pelo estudo empreendido por Milroy (1987), rastreando os grupos de interação aos quais os indivíduos de três comunidades proletárias da cidade de Belfast decidiram pertencer.

Estudos das Redes Sociais de interação, termo traduzido do inglês Social Networks, apresentam uma abordagem complementar sobre as questões da variação e da mudança linguística, visto que as concebem como resultado da interação entre falantes inseridos em determinados contextos sociais e situacionais, fatores essenciais que não podem ser descartados na medição e mensuração da variação/mudança, bem como secundarizam a importância de variáveis linguísticas e sociais descontextualizadas, favorecendo a aproximação das análises à dimensão do cotidiano, fugindo, com isso, de generalizações universais.

Além disso, quando aplicadas ao estudo da linguagem, servem como auxiliares para o esclarecimento dos mecanismos sociais cotidianos favoráveis à manutenção ou mudança da expressão linguística de indivíduos, pois visam explicar por que sujeitos com características tão próximas, como é o caso dos alunos pesquisados neste trabalho - ou seja, mesma idade, escolaridade, estrato social e história de vida aproximados, entre outros fatores - apresentam diferenças tão marcantes em sua expressão oral.

Essas redes representam os graus de contato entre indivíduos que se relacionam cotidianamente de acordo com propriedades como density (densidade), relacionada à estrutura da rede, e multiplexity (multiplexidade), condizente com o conteúdo da rede.

Em Milroy (1987, p. 50), lemos que "uma rede é considerada relativamente densa se um grande número de pessoas se liga umas às outras de diferentes formas" " (tradução minha). Quanto maior for o número de pessoas que se conhecem entre si internamente em um grupo, maior a densidade da rede, informa ainda Milroy (1987), pois, ao se relacionarem avidamente em sua rede, o contato com o exterior é minimizado, uma vez que cada indivíduo tem poucas possibilidades de usar suas relações para contatar pessoas e ser contatado por pessoas de fora dos limites do grupo. Em contrapartida, uma rede em

\footnotetext{
${ }^{2} \mathrm{~A}$ network is said to be relatively dense if a large number of the persons to whom ego is linked are also linked to each other.
} 
que poucas pessoas se conhecem mutuamente é uma rede de tessitura frouxa, com pouca densidade.

Em relação à multiplexidade, a autora considera as características dos laços dentro das redes tão importantes quanto as próprias redes, uma vez que, mesmo estando dentro da mesma ordem, alguns laços podem ser mais influenciáveis que outros.

Dentro desse conceito, Milroy (1987) faz uma bipartição entre multiplexidade e uniplexidade. Um vínculo será uniplex quando um integrante da rede representar um papel apenas em relação ao outro, por exemplo, apenas patrão e empregado. O grau de complexidade aqui é baixo, já que os papéis sociais exercidos pela mesma pessoa não são diversificados, devido aos restritos domínios de atividades sociais.

Será multiplex quando assumir uma gama de papéis, ou seja, sendo patrão, pode ser também vizinho, tio, pastor etc. Milroy (1987, p. 51) comenta: “o mesmo homem pode ligar-se a uma pessoa como colega de trabalho, vizinho, parente ou em outras formas ${ }^{3}$, (tradução minha).

Bortoni-Ricardo (2011) frisa a importância dos papéis sociais para a distinção entre rural e urbano, uma vez que, em localidades rurais, é comum o indivíduo exercer diversos papéis numa mesma comunidade de fala, o que gera uma dependência linguística entre os membros dessa comunidade, ao passo que, em localidades urbanas, os conhecidos podem ser vários, cada um com um papel bem marcado. A autora (2011, p. 94) esclarece: “enquanto o meio urbano caracteriza-se por um alto nível de densidade de relações de papéis, o ambiente em vilarejos apresenta um baixo nível desse tipo de densidade".

Já nos estudos em Belfast, Milroy (1987) atenta para a configuração das redes sociais mediante laços sociais fortes ou fracos. $\mathrm{O}$ estabelecimento de laços fortes acontece por intermédio de vínculos rotineiros e contínuos com parentes, vizinhos e amigos, de modo que o alto nível de intimidade assegure contatos cotidianos. Laços fracos, em outra mão, decorrem de atividades várias, não intensas e sem ligas extremadas.

O produto da soma desses laços resulta na tessitura da rede, a qual, nos aspectos estruturais estabelecidos por Milroy (1987), envolve a densidade e a multiplexidade. Essa tessitura estabelece os elos entre as redes, pois, como mostra a autora, uma rede de alta densidade possui pontos interconexos, ao passo que a redes de baixa densidade apresentam pontos difusos, com grande espaçamento e sem elos de coesão.

\footnotetext{
${ }^{3}$ The same man may be connected to ego as co-employee, neighbour, kin and in many other capacities.
} 
Com isso, observa-se que há um liame entre redes de interação, conservação de variedades e assimilação da língua padrão.

Esses espaços de interação entre os indivíduos são fundamentais para a depreensão da mudança e da manutenção, pois abarcam mecanismos que podem ser tendenciosos tanto para facilitar como para dificultar a mudança linguística. Serem densas ou frouxas implica diretamente nos costumes linguísticos, sobretudo no que concerne à manutenção e à inovação linguística.

Os alunos analisados neste trabalho podem ser inseridos dentro da mesma classe social, notadamente entre os menos favorecidos, entretanto, como bem observa BortoniRicardo (2011), essa classificação não é adequada, pois não considera as diferenças de renda, ocupação, entre outras, por isso o foco em suas redes de interação, que pode trazer luz a diferenças sutis e indicar redes referenciais dos indivíduos em relação ao grau de adesão à cultura hegemônica.

Se laços fortes, inseridos em redes densas, podem reforçar o falar local e laços fracos, traços de redes frouxas, propagar mudança, a fala dos alunos do Colégio Estadual de Paiquerê em direção à norma urbana ou fixada no falar rural encontra aqui uma explicação fundamental. Dentro dessa perspectiva, as noções de difusão e focalização têm papel importante.

Le Page (1980, p. 15-16) estabelece que

Envolvemo-nos em atividades que eu chamo de projeção e de focalização: por meio da fala, projetamos para o grupo social os conceitos que formamos, de modo a fornecer o nosso universo e tentar levar os outros a reconhecerem do que somos feitos. Depois, tentamos trazer os nossos conceitos para foco alheio, de modo a que haja um feedback a partir do tecido social por meio da linguagem. ${ }^{4}$

Dessa maneira, o autor propõe o conceito de difusão como resultado da mobilidade física e social dos falantes que se encontram em área de contato dialetal. Contrariamente, em comunidades estabelecidas há longo tempo onde não há contato dialetal, ocorre a focalização.

Esses conceitos, intrinsecamente ligados às caracterizações das redes sociais, têm implicação direta nos usos linguísticos, especialmente em relação à manutenção e à mudança linguística. As pesquisas citadas (MILROY, 1987; BORTONI-RICARDO,

${ }^{4}$ We engage in activities I call projection and focussing: we project on to the social screen the concepts we have formed, by talking about them, so as to furnish our universe and try to get others to acknowledge the shape of the furniture; we in turn try to bring our concepts into focus with those of others, so that there is feedback from the social screen through language. 
2011; OLIVEIRA, 2014) apontaram disposição para a manutenção e focalização do falar identitário em comunidades cujas redes são isoladas, devido à resistência pela mudança linguística. Em contrapartida, em redes integradas e abertas à mudança foi caracterizada maior difusão.

Podem ser definidas como redes isoladas aquelas restritas à família extensa e a vizinhos próximos e como redes integradas as que são constituídas em contextos sociais amplos.

Dessa maneira, redes isoladas podem ser potenciais favorecedoras do falar identitário; com alto grau de densidade, sua configuração passa a funcionar como mecanismo de resistência à mudança. Essa seria característica, de acordo com Milroy (1987) de redes em áreas rurais, caso do Distrito de Paiquerê, as quais tendem à alta densidade e multiplexidade, conceitos sobre os quais já discorri anteriormente.

Bortoni-Ricardo (2011) certifica a conexão entre o isolamento das redes e a manutenção linguística, tanto em pequenos lugarejos como em localidades metropolitanas territorialmente definidas, cuja coesão social, étnica ou religiosa é alta. E, ainda, a associação existente entre redes de tessitura miúda e a preservação da linguagem minoritária, tanto quanto a ligação entre redes abertas e a linguagem dominante.

Entre alguns adolescentes aqui analisados, em especial os que trabalham fora do distrito, foi possível notar a difusão do falar rural, como ocorrido em Brasília e observado por Bortoni-Ricardo (2011), no sentido de afastamento, como utilizado pela autora, já que não houve, necessariamente, aquisição da norma culta, mas de um falar menos estigmatizado, mais distante do falar rural.

Os informantes INF1, INF6, INF23, INF24 inserem-se em redes externas às comumente rurais, pois trabalham fora do distrito, indo para a cidade diariamente. Já a informante INF7 tem seu trabalho no distrito, mas pode apresentar alguma mobilidade de redes, visto que sua atividade profissional admite contato com pessoas de toda sorte. Informantes como INF15, INF18, INF20, INF21 e INF22, como trabalham apenas no sítio, quase todos tendo seus pais como patrões e sem carteira assinada, marca do trabalho urbano, apresentam contatos mais restritos. Dessa maneira, com os primeiros, a possibilidade de difusão é maior que para os últimos, os quais podem apresentar maior focalização, visto que, como bem observa Bortoni-Ricardo (2005, p. 123), “a fala em comunidades rurais isoladas pode ser considerada como uma forma altamente focalizada do vernáculo rural". 
A questão da focalização e da difusão tem muita relação com a identidade do indivíduo e ao papel social representado. Alguns falantes podem usar uma variedade linguística difusa em suas interações exteriores à sua comunidade de origem, mas manterem um falar focalizado ao interagirem com os seus. Bortoni-Ricardo, comentando estudo de Blom e Gumperz (1972 apud BORTONI-RICARDO, 2011), lembra que a variedade local representa a língua do lar e é uma marca identitária e cultural local, ao passo que o padrão representa valores externos. O método analítico ARS nos responde questões a esse respeito.

\section{A análise com o método da Análise de Redes Sociais (ARS)}

Originalmente utilizada nos sistemas de telecomunicações e computação, procura estabelecer um meio objetivo de identificar conexões (laços ou relações) e pontos (nós ou atores) dentro de um sistema determinado e, com isso, representar padrões estruturais de relações, os quais tanto podem se apresentar como constantes, ou totalmente imprevisíveis e não lineares

É uma metodologia aplicada ao estudo das relações entre entidades e objetos de qualquer natureza, em especial no que tange aos problemas complexos, como a manutenção e mudança linguística, por exemplo, e por isso viável para os estudos sociais.

De acordo com Hanneman e Ridle (2005), a ARS caracteriza-se fundamentalmente por sua ocupação com dados que expressam relações entre objetos diversos, ocasionando um deslocamento de foco analítico. Ou seja, a abordagem tradicional nas ciências humanas centra-se nos atributos individuais, ao passo que a ARS vislumbra as relações estabelecidas por esses indivíduos com demais participantes em determinado contexto social.

Utilizar a ARS como método analítico é mais propício ao tratar da fala, ato individual, pois indivíduos não são tratados como equi-iguais, já que são, faticamente, extremamente diferentes.

Em redes, tudo isso está relacionado, imbricado, sendo os dados dependentes uns dos outros e a mensuração dessa imbricação pode se dar por meio de dois tipos de análise: as sociocêntricas e as egocêntricas. Utilizo as segundas por focalizarem os efeitos da rede sobre as atitudes individuais e comportamentos condicionantes, ou seja, por preocuparse com os efeitos de uma rede sobre atitudes individuais, por exemplo, como o contexto e a estrutura social afetam as liberdades individuais e, nesse caso em especial, como as redes afetam a configuração da fala do adolescente que reside em Paiquerê. 
A quantificação das redes pode ser feita por alguns meios. Neste trabalho, utilizo o Egonet, um software livre criado por Christopher McCarty, da Universidade da Flórida - EUA, que, além de outras funções não relevantes para este trabalho, quantifica os contatos de pessoa determinada, por meio da identificação de conexões (laços ou relações) e pontos (nós ou atores) dentro de sua rede egocêntrica ou pessoal, estabelecendo os padrões estruturais de sua interação e, com isso, definindo a constância e a aleatoriedade de suas relações.

Para obter o mapeamento das redes dos informantes, foi feito um questionário básico de três perguntas diretas: "Quais são as cinco pessoas mais importantes na sua vida? Quais foram as cinco pessoas com quem mais conversou desde o início da semana? Se ganhasse um prêmio hoje, com quem o dividiria?". Obtidos os nomes, esses foram lançados no programa para a definição de quem se relaciona com quem na rede.

Cada informante foi convidado a responder a afinidade que cada membro de sua rede pessoal tem com o outro. Exemplificando pela INF1: ela citou marido, avó, patroa, mãe e irmão, nessa ordem, como os membros de sua rede pessoal de interação. Questionei se o marido, primeiro membro citado, interagia com avó, patroa, mãe e irmão; na sequência, se a avó se relacionava com o marido, patroa, mãe e irmão; assim sucessivamente e com todos os vinte e quatro adolescentes.

O resultado, apresentado na sequência, permite caracterizar as redes desses informantes, no que concerne à densidade e à complexidade, bem como a qualidade dos laços, se densos ou frouxos, o que é de fundamental importância para a manutenção ou a mudança do falar identitário em favor de um outro que se deseje alcançar, como a mudança do falar rural para o falar urbano.

Ademais, conhecer os laços permite entender como as redes agem em relação ao desejo, consciente ou não, que o falante tem pela manutenção ou mudança. Em relação a isso, alicerço-me em Bortoni-Ricardo (2014, p. 130), quando assegura que "em comunidades de tessitura miúda, onde praticamente todas as pessoas interagem entre si, a pressão normativa é maior. Em comunidades de redes mais esparsas, de tessitura larga, a pressão normativa é menor".

Vejamos como ficaram alguns desses mapas: 
Rede Pessoal INF1

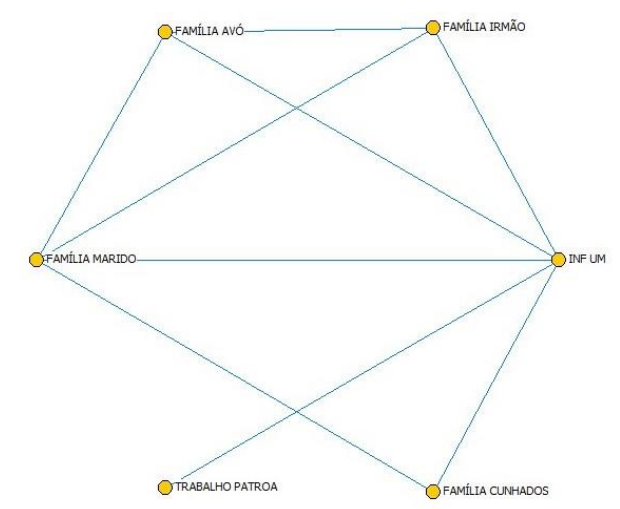

Rede Pessoal INF3

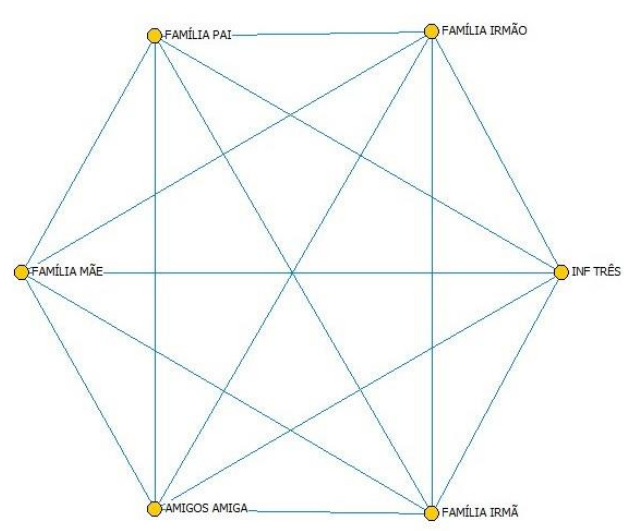

Rede Pessoal INF5

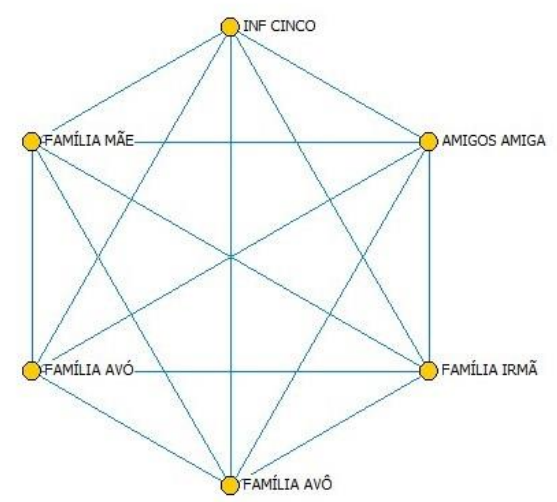

Rede Pessoal INF2

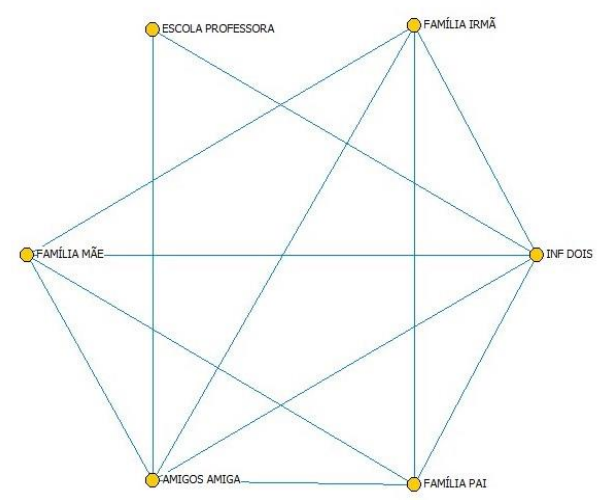

Rede Pessoal INF4

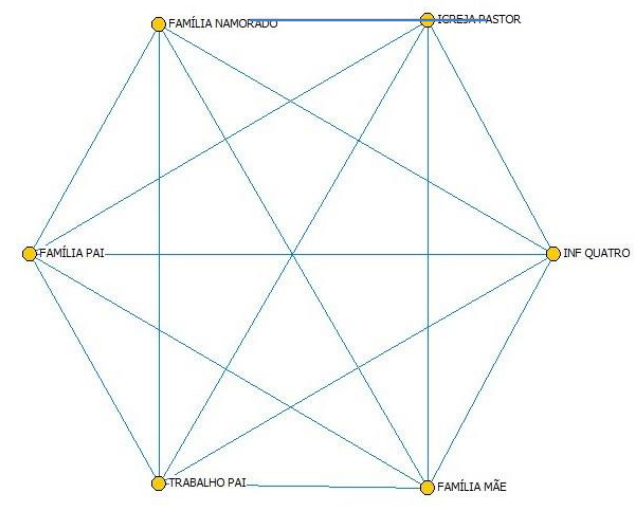

Rede Pessoal INF6

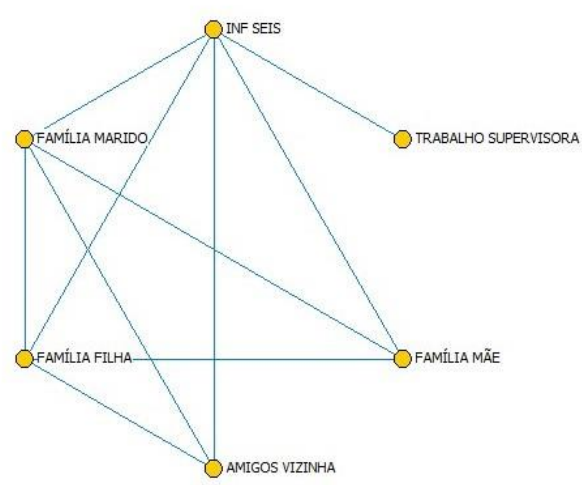

Rede Pessoal INF7

Rede Pessoal INF8 


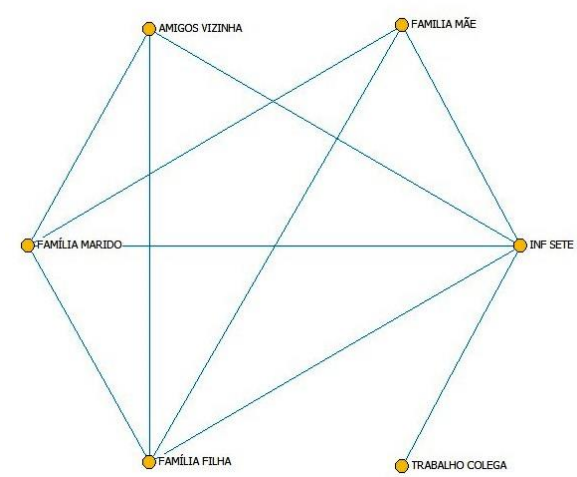

Rede Pessoal INF9

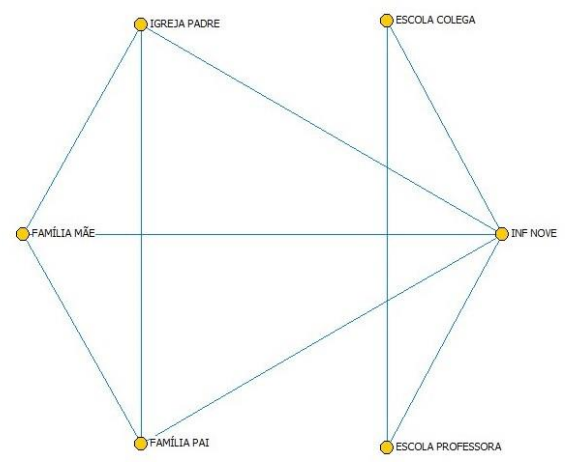

Rede Pessoal INF11

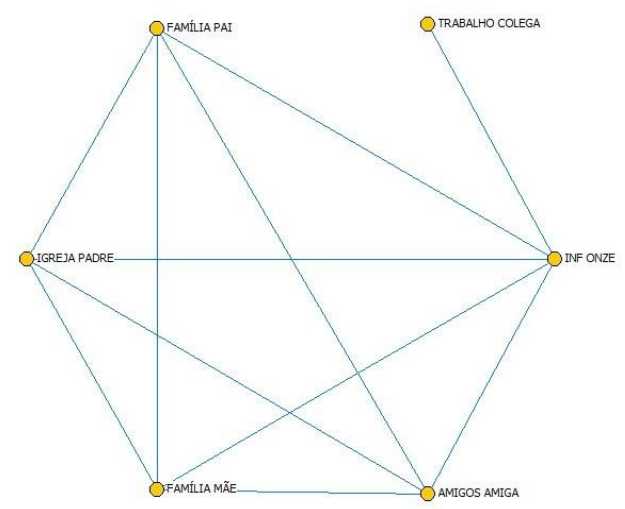

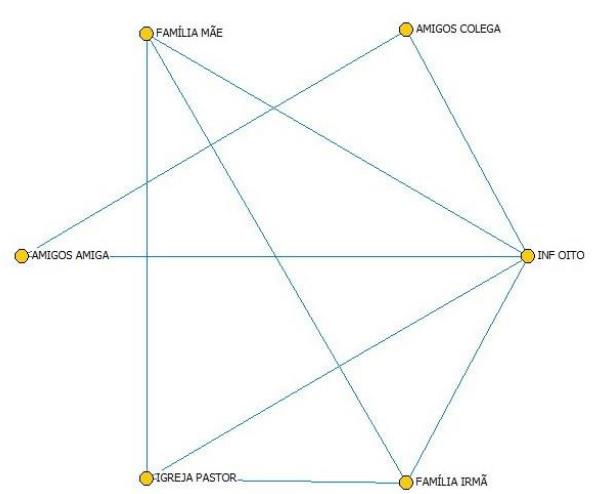

Rede Pessoal INF10

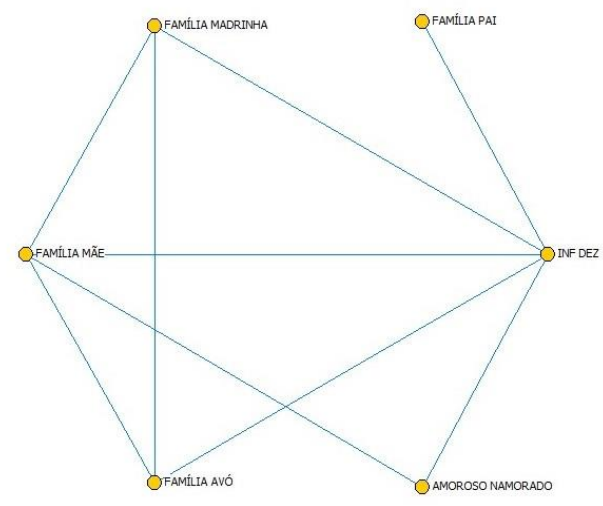

Rede Pessoal INF11

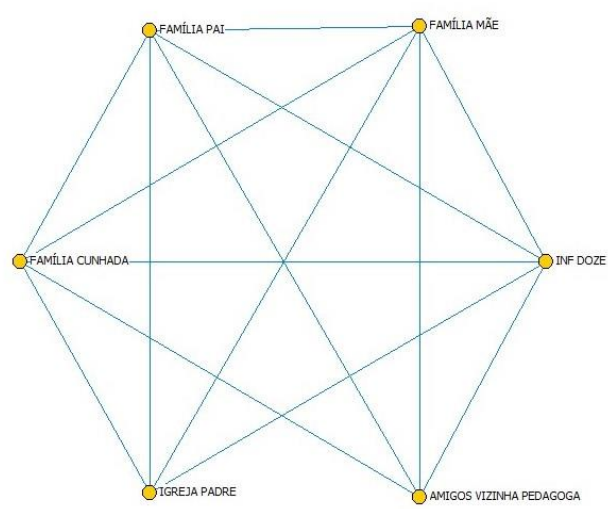


Rede Pessoal INF13

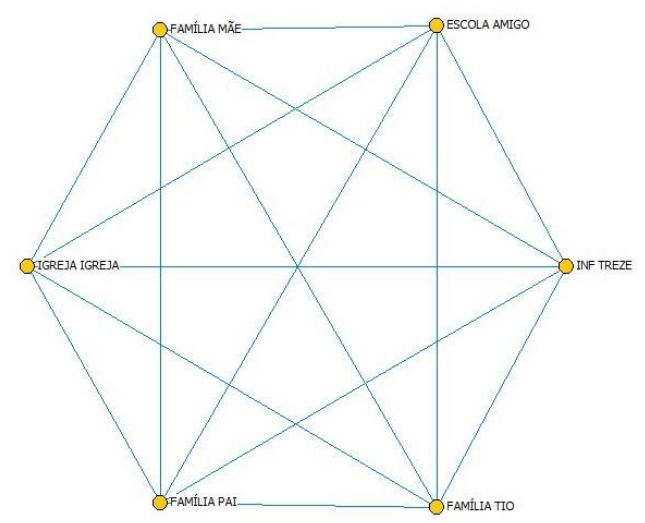

Rede Pessoal INF15

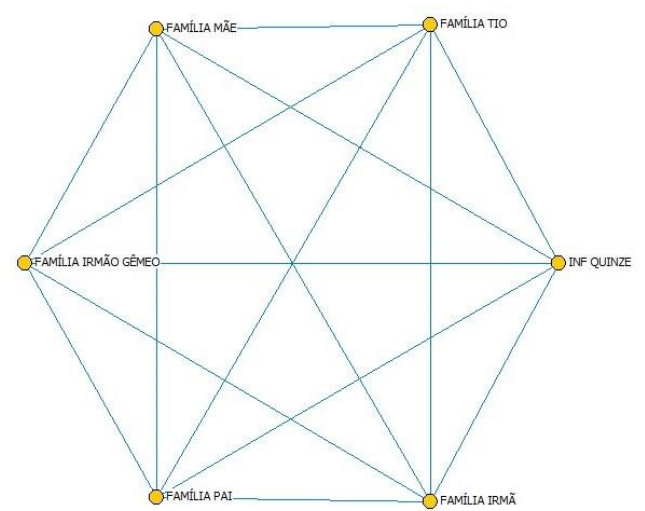

Rede Pessoal INF17

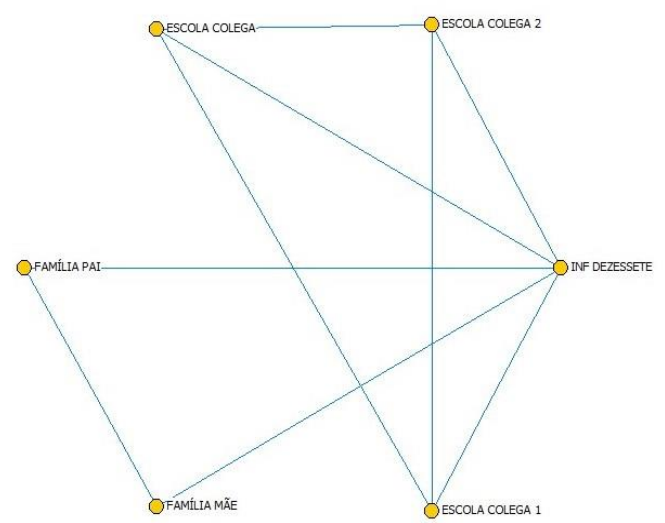

Rede Pessoal INF14

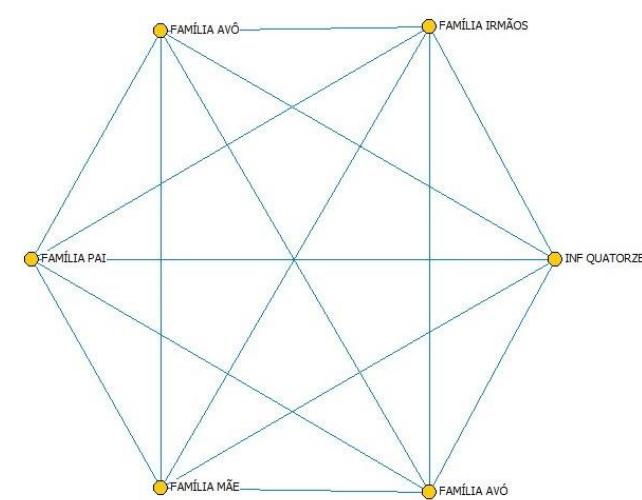

Rede Pessoal INF16

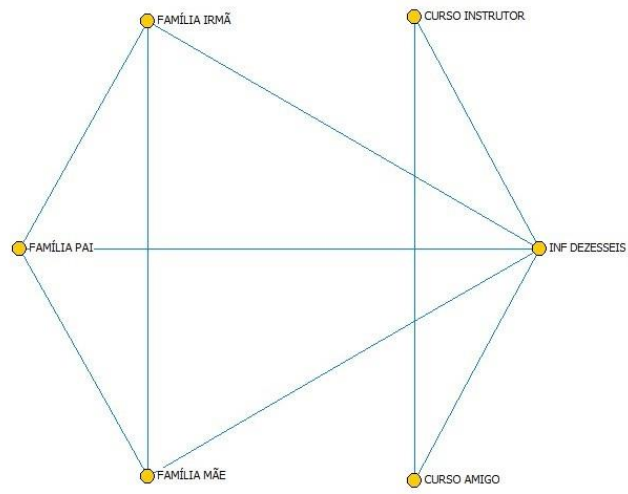

Rede Pessoal INF18

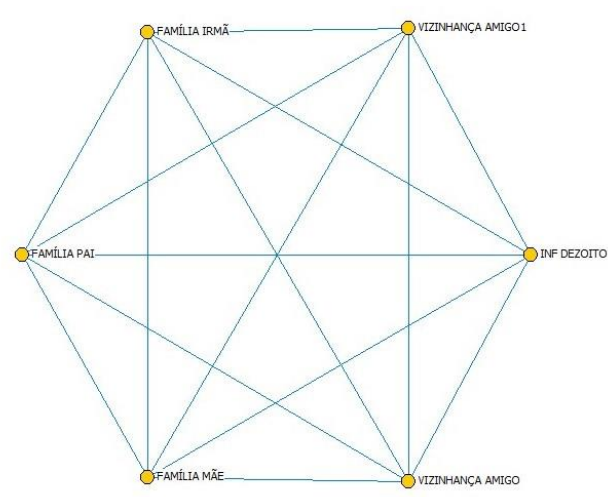


Rede Pessoal INF19

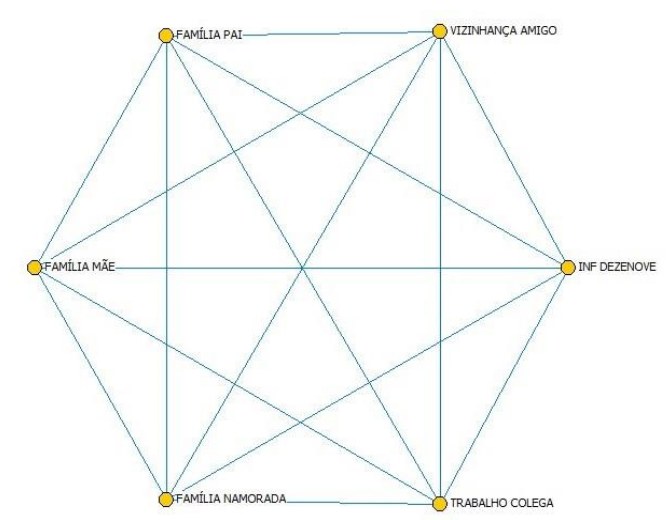

Rede Pessoal INF21

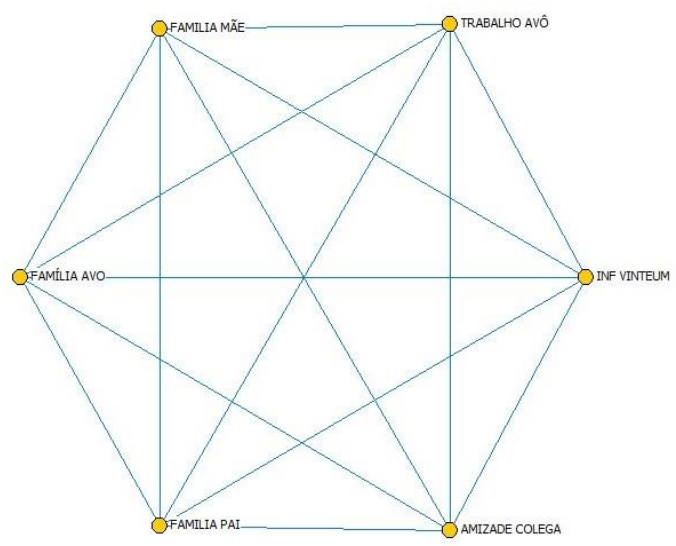

Rede Pessoal INF23

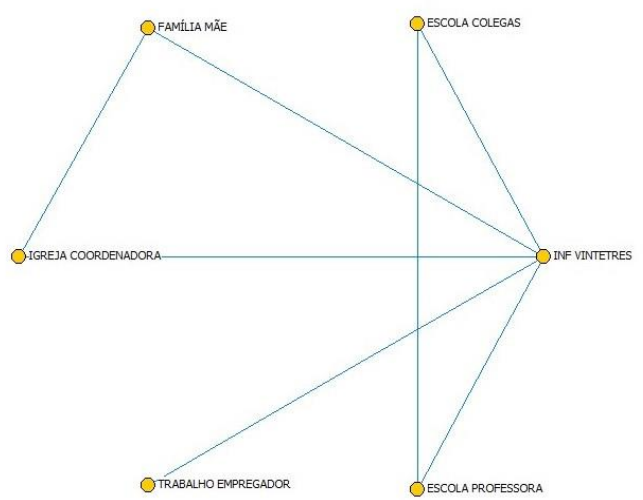

Rede Pessoal INF20

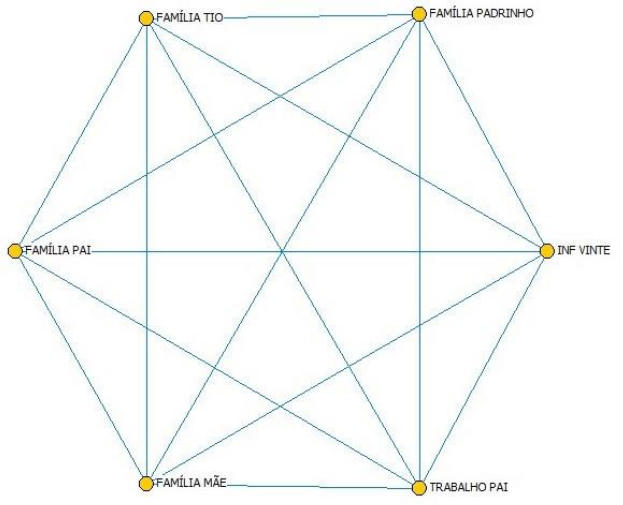

Rede Pessoal INF22

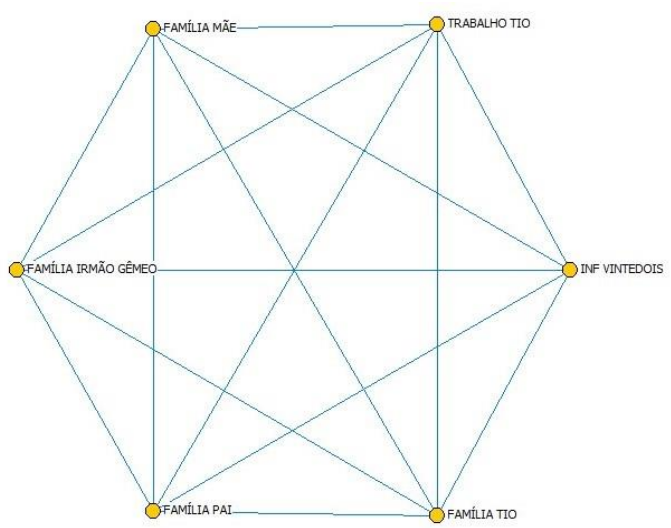

Rede Pessoal INF24

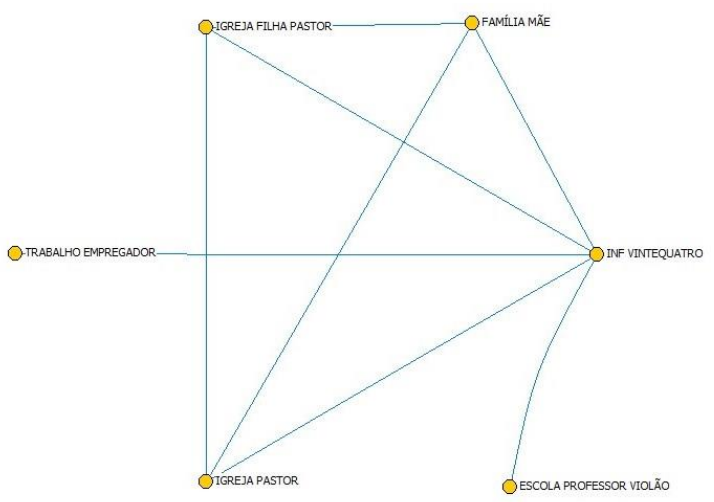

Fonte: a própria autora 
O mapa do INF24 é o único a apresentar dois laços que não se cruzam. Dessa maneira, sua rede pessoal pode ser caracterizada como frouxa, uma vez que não apresenta redundância de vínculos e há mais de um laço fraco, multiplex, que se abre para o contato exterior. Essa pode ser a causa da aproximação total com o falar urbano, pois tais redes favorecem a adesão à cultura de prestígio e, com isso, a aproximação ao falar urbano.

Bortoni-Ricardo (2005, p. 88) justifica tal postura ao relatar que

Quando o individuo consegue ascender socialmente, sua rede de interação torna-se mais heterogênea, e, consequentemente, de tessitura mais frouxa. O processo de difusão dialetal se intensifica, e o falante vai se aproximando da norma culta, adquirindo uma gama mais ampla de registros $[\ldots]$.

As redes de INF1, INF7, INF9, INF10, INF11 e do INF23 trazem pelo menos um laço fraco, aberto para o exterior, além de não haver ligação entre todos os membros de sua rede pessoal. Podem, portanto, também se caracterizar como redes frouxas, uma vez que há grandes possibilidades de interferência externa. Associo esse tipo de rede a uma prática linguística rurbana, ou seja, é possível que, em uma alocação final desses informantes no contínuo de urbanização, posicionem-se em pontos rurbanos, mais próximos de um extremo ou de outro, mas não especificamente nas pontas da linha.

A rede trabalho, ainda que relevante, pode ter características distintas, o que afeta a configuração linguística dos informantes. Como exemplo, cito a INF7 e INF23. A INF7, cujo local de trabalho é o próprio distrito, apresenta traços do falar rural, como "Tem qui sê compreto?", ao passo que o INF23, que trabalha no maior centro comercial de Londrina, expressa-se bem próximo do falar urbano, mesmo nos últimos momentos da entrevista, em que, relaxado, já apresentava o seu vernáculo, como em: "aí ela dexô um pidido qui era pra cuidarmos do filho mais novo dela qui é o qui mora im Santa Catarina".

Tal discrepância na fala de informantes que têm a rede trabalho em suas interações pode ser respondida por fatores conjugados. Ainda utilizando os INF7 e INF23, o local de trabalho e o grau de letramento dessas redes influenciam uma mudança ou manutenção do falar rural. A INF7 trabalha em um mercado localizado na área urbana do distrito, tendo a função de remarcar preços e repor mercadorias. Ainda que seus patrões tenham um status social superior, também moram no distrito, e as colegas de trabalho são todas de lá. O grau de letramento dominante é mínimo. Já o INF23 trabalha na administração de um shopping center. Todos os seus colegas de trabalho utilizam o falar urbano, quando 
não, um rurbano situado bem próximo da ponta do contínuo de urbanização. Esses fatores são, de fato, preponderantes na diferença marcante entre as falas desses dois informantes.

A INF1 tem no trabalho uma motivação para a alternância de norma. Ela mesma, em sua entrevista, conta-me que uma de suas patroas, professora aposentada da UEL, cobra-lhe um falar mais próximo do padrão. Em Bortoni-Ricardo (2011), vemos que é possível associar este fato ao que Labov chama de "incongruência de status", uma vez que a informante, na busca pelo uso do falar urbano, está adotando os valores de um grupo externo ao seu, um grupo que tem como referência, e, nessa busca, alterna entre o rural e o urbano, ficando no rurbano, como se vê em "Intão, o qui eu assisto mais é os canais pagos, né, eu gosto do History, eu gosto do di filmes, todos os canal di filmi.”. Devido a esse contato com patroas diferentes, suas redes são frouxas e com laços uniplex.

A INF6 tem uma ligação com o trabalho, personificada na pessoa de sua supervisora, bastante forte. Sua rede é frouxa, com laços uniplex na maioria das interações. A INF7 insere-se em uma rede relativamente frouxa, já que existem laços frouxos, com pontos difusão.

Em relação às INF2, INF8, INF12 e aos INF16 e INF17, ainda que a maioria dos laços seja interligada, há pontos desconectados, sem elos de coesão, como vimos em Milroy (1987), o que possibilita a intervenção externa não categórica. Essa abertura caracteriza suas redes como relativamente densas e os laços como relativamente fortes, o que pode ser responsável pelo falar rurbano, pois as expressões ora estão mais próximas do falar urbano, ora aproximadas do rural.

A INF2, por exemplo, apresenta essa alternância, a exemplo de: "Ué, por causo qui eu acho bem bunito aquelas praia, eu sempre tive vontadi di conhecê-las.”. A expressão "por causa quil” não é bem aceita socialmente, por isso, um traço descontínuo, contrastando com o uso de acordo com a prescrição da norma padrão do pronome oblíquo (conhecê-las). Ainda há a falta de concordância nominal — de gênero e de número — em: "bem bonito aquelas praia", traços graduais, pois aparecem na fala não monitorada da grande maioria dos falantes.

$\mathrm{Na}$ fala de INF8, temos "é ligaro né pu um zero nove da pulicia e falo que tinha qui é um bicho perigoso dentro da casa qui ia pegá ele". No primeiro uso do verbo na terceira pessoa do plural, há concordância, entretanto, ocorre a desnasalização, o que, de acordo com Bortoni-Ricardo (2011), é uma das marcas do falar rural. Além disso, não ocorre, no segundo verbo, a concordância com a terceira pessoa do plural subentendida. 
Essa característica rurbana também é específica de zonas periféricas das grandes cidades, local em que a informante residiu por um período antes de morar na ZRD.

Já as redes de INF3, INF4, INF5 e de INF13, INF14, INF15, INF18, INF19, INF20, INF21 e INF22 são densas, já que todos os membros interagem entre si. A influência de fatores exteriores é dificultada pelos laços fortes, multiplex. Todos os pontos são conectados. Suas redes são, portanto, de tessitura miúda.

A INF4, por exemplo, tem um laço característico das redes densas, que é a multiplexidade dos papéis: seu pai é também seu patrão. Mesmo fazendo cursos e tendo namorado, essas redes são ligadas às outras, o que fixa a densidade total de sua rede de interações. A mãe é seu modelo, sua referência profissional. Única mulher com essa característica de vínculo, junta-se aos meninos, pois INF15, INF18, INF19, INF20, INF21 e INF22 têm em comum os pais ou algum familiar representando mais de um papel em suas interações, marca de redes de tessitura miúda.

A família tem um peso grande para a maioria desses informantes, como a INF3 que tem na mãe seu grande modelo de vida, sendo a rede dominante não só nas interações, bem como em relação ao referencial a ser seguido. O INF19 tem a namorada como uma referência para um falar mais apurado e alega "quando tô cum ela eu cuido mais do jeito di falá.”

Cada um dos informantes tem uma referência, um modelo a ser seguido, representado pelo ponto central de suas redes de interação. Esse ponto central é determinante para o processamento de sua fala, para seu desenvolvimento linguístico. Descortinar isso é fundamental para estabelecer a identidade dos alunos em sala de aula e, por meio disso, empreender soluções para o ensino-aprendizagem de Língua Portuguesa.

\section{ARS e Ensino: conjugação}

A análise que fiz mostrou, como já destacado, o quanto as redes de interação social determinam a configuração linguística de meus informantes, de origem rural, e, não obstante isso, agem como principal organizador da aproximação ou do afastamento do falar rural. ${ }^{5}$

Além da confirmação de uma característica inerente à faixa etária que me propus investigar, que é o sentido de pertencimento a um grupo, as relações de identidade

\footnotetext{
${ }^{5}$ Importa saber que o trabalho completo, do qual origina-se esse recorte, alia às redes sociais a questão do letramento.
} 
demarcando todas as formações do indivíduo, quer linguísticas, sociais, de caráter ou de orientação geral.

Diante das constatações aqui apresentadas, são pertinentes as considerações de Bortoni-Ricardo (2005, p. 181) sobre o descaso da escola no acesso do aluno à normapadrão, uma vez que não favorece meios de exposição a exemplos dessa variedade em sala de aula, a despeito "da grande ênfase que a pesquisa sociolinguística tem dedicado às consequências educacionais da variação linguística".

A questão é muito mais abrangente. Oferecer o acesso à sistematização da língua materna a alunos tão heterogêneos da maneira homogênea como vem sendo praticado pode ser uma causa do insucesso apresentado por informantes como INF3, INF7, INF20, entre outros.

Em um exemplo claro disso, Bortoni-Ricardo (2009), ao documentar a marcação de plural nos sintagmas nominais somente uma vez e denominá-la de regra gradual, já orienta para a necessidade de isso ser muito bem trabalhado em sala aula, de modo a levar os alunos que têm como identidade a variante não redundante em sua linguagem oral, na espontaneidade de suas redes de interação, a capacitarem-se ao monitoramento e, com isso, habilitarem-se a usar a variante com plurais redundantes na escrita e na fala formal.

Mas há algo ainda mais patente e que convém ser citado. Convivi com os professores do Colégio Estadual de Paiquerê como pesquisadora e como colega de trabalho, já que atuei como docente em duas oportunidades durante a fase da pesquisa. Nas conversas em sala de aula, vi e conversei com professores que se situam em pontos muito próximos do rural se alocados no contínuo de urbanização. Entre eles, uma das professoras de Língua Portuguesa.

Em vários momentos, alguns alunos mais ousados chegaram a questionar para mim "a fala errada" da professora tal. Questionavam e duvidavam de sua capacidade, portanto, não a respeitavam.

Camacho (2010, p. 42) assevera ser uma necessidade a todo e qualquer indivíduo ter "interiorizadas em sua competência linguística, as formas alternativas da variedadepadrão, ou de prestígio, e da variedade não padrão, que pode também ser estigmatizada, sobre as quais ele pode operar seleção conforme variam as circunstâncias de interação.”, e completa colocando como papel da escola o cuidado para que as crianças tenham, desde a tenra idade, o acesso ao ensino das formas da variedade padrão, de maneira que possam, quando adultas, incorporar formas padrão ao seu repertório linguístico e serem, dessa maneira, capazes de adequar sua fala aos contextos exigidos pelo momento interacional. 
Como poderia a professora citada mencionar a necessidade de adequação aos contextos linguísticos exigidos, não conseguindo fazê-la?

Castilho (2010, p. 209 ), a esse respeito, discorre

Tendo a escola a obrigação de ensinar o português culto, e levando em conta o ingresso nela de muitos alunos que praticam a variedade popular, é evidente que os professores têm de conhecer bem ambas as variedades para desenvolver estratégias de, respeitando a popular, expor os alunos à variedade culta. Ou seja, é preciso que professores e alunos conheçam bem ambas as variedades para escolher com adequação aquela que melhor corresponda à situação de fala: em casa, adota-se a norma familiar, qualquer que seja ela; falando com estranhos, adota-se o português padrão. É nessa espécie de 'bilinguismo interno', manejado com naturalidade em sociedades desenvolvidas, que se assenta uma percepção democrática de uso da língua materna (grifos meus).

No meu modo de olhar, estaria aqui um problema sério dos cursos de formação de professores, instaurado pela proliferação de cursos de Pedagogia e de Letras, virtuais e presenciais, sem que haja critérios didático-pedagógicos consistentes. Além disso, o sistema de seleção de professores para as vagas abertas pelo processo de PSS (processo seletivo simplificado) no Paraná, por meio do qual são selecionados professores sem avaliação de sua condição linguística e didática, não ajuda no desenvolvimento da escola que se deseja construir e das aulas propícias ao desenvolvimento de um indivíduo proficiente em sua língua materna.

A formação de professores mais bem treinados também deve abarcar a abordagem da variação linguística em sala de aula da maneira adequada. Nem tanto ao céu, nem tanto à terra. Não é o caso de lançarem as gramáticas ao fogo, em uma inquisição linguística, nem de privilegiar tão somente a gramática normativa.

Adequação é a palavra.

O ensino de Língua Portuguesa deve levar em consideração a variedade trazida pelo aluno para a sala de aula, pois é sua identidade e traz enraizada suas redes de interação. $\mathrm{O}$ efeito drástico que há hoje ao tentar impor uma variedade sobre a outra acaba por afastar o aluno do interesse em buscar novas formas, a fim de se adequar, uma vez que isso implica um afastamento de suas origens, na maior parte dos casos.

Mostrar ao aluno o leque de possibilidades linguísticas à sua disposição, exemplificando situações e usos, ao contrário, possibilitará a ele o reconhecimento da riqueza da língua e favorecerá o desejo de conhecer, de se aprimorar e ser proficiente em sua língua mãe. 
Respeitar a variedade trazida pelo aluno não significa, portanto, negar-lhe o acesso às formas prestigiadas da língua. Como bem advoga Gagné (2002, p. 230):

Trata-se, para a escola, sem lançar juízo de valor sobre os diferentes usos e sem querer eliminar os usos espontâneos e legítimos, de oferecer ocasiões de utilização dos elementos ouvidos e compreendidos, que fazem parte da competência passiva das crianças. O objetivo não é substituir um uso por outro, mas, antes, familiarizar a criança com o emprego de formas prestigiosas.

Levar o aluno de um circuito rural ou rurbano, como de Paiquerê, a ter maior acesso às normas mais bem aceitas socialmente é favorecer sua mobilidade social. É assim que as coisas funcionam, já que “[...] uma variedade linguística 'vale’ o que 'valem” na sociedade os seus falantes, isto é, como reflexo do poder e da autoridade que eles têm nas relações econômicas e sociais" (GNERRE, 1985, p. 4, grifos do autor).

A escola deverá proporcionar meios para que esse alunado atinja tal patamar de adequação, e não será impondo a leitura de um clássico da literatura sem um trabalho prévio de contextualização e uma atividade real, como o proposto pela docente no colégio em que fiz a pesquisa, que obterá isso. Bortoni-Ricardo (2014) apresenta algumas tarefas ${ }^{6}$, do início da escolarização ao final do Ensino Médio, que podem, e eu acredito que devem, ser subsidiadas pela Sociolinguística.

Dentre elas, destaco:

i) em relação às tarefas para o início da escolarização, o item 1.1 "desenvolver recursos para facilitar a integração entre os conhecimentos de língua oral que os alunos trazem consigo para a escola e as competências de leitura, escrita e oralidade que vão adquirir ou aprender" (p. 163), pois é na base que o ensino deve atuar no sentido de promover uma consciência de adequação linguística e a confiança, pois, ao buscar a integração entre os conhecimentos internalizados e os a adquirir, respeita-se a história e a identidade do aluno.

ii) Ainda dentre as tarefas do início da escolarização, enfatizo o item 1.10 “distinguir entre regras variáveis no repertório dos alunos as que têm caráter regional das que têm caráter idiossincrático e elaborar estratégias pedagógicas com a variação linguística regional; social e funcional” (p. 164), pois ele vem emparelhar com o 1.1 na busca pela valorização da variedade do aluno e a apresentação de outras variedades.

\footnotetext{
${ }^{6}$ Para conhecimento de todas as tarefas, ler Bortoni-Ricardo (2014). Os dados completos encontram-se nas referências finais desta tese.
} 
iii) No que tange ao desenvolvimento de estratégias de produção escrita, o ponto 4.2 "incentivar os alunos a produzir textos orais anteriores aos escritos", uma vez que, com isso, é possível clarear as diferenças substanciais entre a fala e a escrita e a importância de adequação tanto em um quanto no outro formato de expressão linguística.

Algumas coisas estão sendo feitas para isso e os próprios documentos oficiais orientam as ações nesse sentido, como se vê nesse excerto dos PCN (BRASIL, 1998, p. 29)

A variação é constitutiva das línguas humanas, ocorrendo em todos os níveis. Ela sempre existiu e sempre existirá, independente de qualquer ação normativa. Assim, quando se fala em "Língua Portuguesa", está se falando de uma unidade que os constitui de muitas variedades. Embora no Brasil haja relativa unidade linguística e apenas uma língua nacional, notam-se diferenças de pronúncia, de emprego de palavras, de morfologia e de construções sintáticas, as quais não somente identificam os falantes de comunidades linguísticas em diferentes regiões, como ainda se multiplicam em uma mesma comunidade de fala.

Refletindo o mesmo juízo, o documento também assevera que

a aula deve ser o espaço privilegiado de desenvolvimento de capacidade intelectual e linguística dos alunos, oferecendo-lhes condições de desenvolvimento de sua competência discursiva. Isso significa aprender a manipular textos escritos variados e adequar o registro oral às situações interlocutivas, o que, em certas circunstâncias, implica usar padrões mais próximos da escrita (BRASIL, 1998, p. 30).

Faz-se necessário estabelecer uma proposta que favoreça o estudo da língua de acordo com a realidade do aluno, de modo a incentivá-lo a conhecer uma variedade diferente da sua, sem que haja preconceito, respeitando sua identidade respeitada, e de modo a desconstruir o modelo de aula como apontado por Soares (2002), cujo método trabalha a linguagem tão só de forma prescritiva.

Para que tal questão seja solucionada, a escola deve passar a encarar a realidade linguística atual. Deve atuar no sentido de proporcionar a inclusão, uma vez que hoje, como vemos em Scherre (2008, p. 42), "banem-se da escola não as formas linguísticas consideradas indesejáveis, mas, sim, as pessoas que as produzem".

Antunes (2009) esclarece que, ainda que as instituições governamentais venham trabalhando no sentido de empreender uma escola mais formadora e eficiente, ao atuar na formação e capacitação dos professores e nas avaliações, em sala de aula a atividade 
pedagógica, na maioria das vezes, permanece inalterada. Segundo a autora, o trabalho com a oralidade, a escrita, a leitura e com a gramática é superficial. A gramática, além de ser trabalhada de maneira descontextualizada, é tida como inflexível, petrificada, pertencente a uma língua supostamente uniforme e estável, “irremediavelmente 'fixada' num conjunto de regras que, conforme constam nos manuais, devem manter-se a todo custo imutáveis [...], como se o processo de mudança das línguas fosse apenas um fato do passado, algo que já aconteceu e não acontece mais." (ANTUNES, 2009, p. 32).

Gagné (2002, p. 197), em relação ao ensino do Francês, conclui algo nesse sentido quando alega

Em geral, a pedagogia centrada no código linguístico repousa numa perspectiva da qualidade da língua que é normativa e frequentemente purista. Esta perspectiva, centrada na escrita, concebe a língua como um código homogêneo, único e intrinsecamente superior: aquele que é descrito nos dicionários e nas gramáticas. $\mathrm{O}$ objetivo prioritário, senão único, que ela visa consiste em adquirir tal código. Em geral a pedagogia tradicional com a qual muitas gerações de francófonos têm aprendido sua língua.

O espaço em sala de aula, além de alfabetizar e letrar, deve servir como arena em que seja abordada a variação linguística de forma arraigada e clara, contribuindo para a erradicação do preconceito linguístico e para a derrocada do mito que classifica a língua portuguesa como uniforme e homogênea.

Com essa orientação no bojo, os projetos de pesquisa dos quais participo servem de exemplo de trabalhos cuja metodologia vem promovendo um melhor direcionamento das aulas de língua portuguesa.

Cito, primeiramente, o projeto VALE - Variação linguística na escola, desenvolvido pelos docentes e discentes do curso de Letras do Centro de Letras e Ciências Humanas da Universidade Estadual de Londrina, coordenado pela professora Joyce Baronas.

O projeto objetiva, principalmente, elaborar materiais didáticos que contemplem conteúdos sobre as diferentes formas linguísticas orais e escritas do português do Brasil, abordando as diferentes variedades existentes no país, com vistas a, além de colaborar para a eliminação do preconceito linguístico, fornecer subsídios ao professor de língua materna para tratar adequadamente a variação da língua em suas aulas, favorecendo o aluno a ser proficiente em sua língua, ou seja, adequar-se ao contexto comunicativo e ser capaz de utilizar as diferentes variedades esperadas para as diferentes situações sociais. 
O projeto está em sua fase final, pois o material didático organizado pelos participantes está em vias de ser publicado. Primeiramente, as reuniões serviram para o embasamento teórico, depois foram analisados os documentos oficiais estaduais e nacionais, no que tange às orientações em relação ao tratamento da variação linguística, sendo, sequencialmente, analisadas as coleções de livros didáticos aprovadas pelo PNLD (Programa Nacional do Livro Didático) para o triênio 2011-2013.

Nas análises dos livros didáticos, a equipe do VALE observou a pouca alusão à variação social e à variação histórica, pois as coleções, quando tratavam do assunto, faziam-no falando da variação regional e estilística.

O passo seguinte foi elaborar atividades didáticas abordando os tipos de variação. Essas foram discutidas em equipe, aprimoradas e levadas às salas de aulas para testagem. As aprovadas estão agora em um capítulo no prelo, na expectativa de irem para as salas de aula e mudarem um pouco a realidade educacional no país.

O outro projeto é o PONTES, coordenado pela professora Stella Maris BortoniRicardo e alocado na Faculdade de Educação da Universidade de Brasília, cujo objetivo é investigar o processo de familiarização de professores em formação inicial ou continuada com os estudos de Sociolinguística de viés educacional, de modo a promover o empoderamento desses profissionais. As reuniões promovem a discussão e a apresentação de trabalhos práticos em sala de aula, promovidos pelos integrantes do heterogêneo grupo do projeto, que está, também, em fase de conclusão.

Ambos têm sido muito ditosos em seus procedimentos metodológicos, mostrando apropriadas alternativas para a mudança necessária e premente nos moldes das aulas hoje praticadas.

\section{Considerações finais}

Sobre tudo o que foi aqui discutido e relatado, a conclusão a que se chega é a trivial: continuar o ensino da forma como se procede hoje não é mais possível. E trabalhar com as Redes de Interação pode ser um caminho para melhorar tal conjutura, uma vez que dá um panorama da realidade linguística dos alunos. É essencial que este tipo de estudo se expanda a fim de abranger o maior número possível de localidades, até que sejam mapeadas todas as esferas.

A análise das redes sociais é, sem dúvida, um instrumento apropriado para saber como trabalhar em sala de aula as peculiaridades apresentadas em cada rede, como a 
escola deve proceder para conduzir os indivíduos com esses pormenores a uma adequada capacidade linguística que lhes assegure competir e ascender socialmente.

Há outros trabalhos, projetos, programas, certamente, desenvolvendo-se nesse sentido pela imensidão que é nosso Brasil. Anseio pela mudança que virá ao germinarem as sementes daquilo que vimos plantando agora.

Mas o que importa é que começamos, e como já disse Rosa (2001, p. 440), “Todo caminho da gente é resvaloso. Mas; também, cair não prejudica demais — a gente levanta, a gente sobe, a gente volta! Deus resvala? Mire e veja. Tenho medo? Não. Estou dando batalha".

\section{Referências}

ANTUNES, Irandé. Aula de português: encontro e interação. 7. ed. São Paulo: Párabola Editorial, 2009.

BORTONI-RICARDO, Stella Maris. Nós cheguemu na escola, e agora? Sociolinguística e educação. São Paulo: Parábola Editorial, 2005.

Educação em língua materna: Sociolinguística em sala de aula. 6. ed. São Paulo: Parábola Editorial, 2009

Do campo para a cidade: estudo sociolinguístico de migração e redes sociais. São Paulo: Parábola Editorial, 2011 (1985).

Manual de Sociolinguística. São Paulo: Editora Contexto, 2014.

CAMACHO, Roberto Gomes. Uma reflexão crítica sobre a teoria sociolinguística. DELTA, São Paulo, v. 26, n.1, p. 141-163, 2010

CARAVEDO, Rocio. Principios del cambio lingüístico: una contribución sincrónica a la lingüística histórica. RFE, LXXXIII, 1. -2., págs. 39-62, 2003.

CASTILHO, Ataliba T. de . Nova gramática da língua portuguesa. São Paulo: Contexto, 2010.

GAGNÉ, Gilles. A norma e o ensino da língua materna. In.: BAGNO, M.; GAGNÉ, G.; STUBBS, M. Língua materna: letramento, variação e ensino. São Paulo: Párabola Editorial, 2002.

GNERRE, Maurizzio. Linguagem, escrita e poder. São Paulo: Martins Fontes, 1985.

GOODENOUGH, Ward Hunt. Cultural anthropology and linguistics. In: Garvin, Paul L. (Hg.): Report of the Seventh Annual Round table Meeting on Linguistics and Language Study. Washington, D.C.: Georgetown University, Monograph Series on Language and Linguistics, n. 9, pp. 167-173, 1957.

GUMPERZ, J. The speech community. In: GIGLIOLI, P. (Org.). Language and social context. Londres: Penguin Books, 1972.

HANNEMAN, Robert; RIDLE, Mark. Introduction to social network methods. 2005. Disponível em: <http://revista-redes.rediris.es/webredes/>. Acesso em: 18 fev. 2014 
LABOV, William. Princípios del cambio linguístico: Volumen 2: factores sociales. Madrid, Editorial Gredos, 2006.

Padrões sociolinguísticos. São Paulo: Parábola Editorial, 2008 (1972).

LE PAGE, Robert. Projection, focusing and diffusion. York Papers in Linguistics, University of York, v. 9, 1980.

MILROY, Lesley. Language and social networks. 2 ed. Oxford: Blackweel, 1987 (1980).

MILROY, Lesley; MILROY, James. Linguistic change, social network and speaker innovation. Journal of Linguistics, Cambridge, Cambridge University Press, v. 21, p.339-384, 1985

OLIVEIRA, Eliane Vitorino de Moura. Eu sou porque nós é ou eu sou porque nós somos? A variação da concordância adolescente. Nova Edições Acadêmicas, 2014.

ROSA, João Guimarães. Grande Sertão: Veredas. Rio de Janeiro: Nova Fronteira, 2001[1956].

SCHERRE, Maria Marta Pereira. Doa-se lindos filhotes de poodle: variação linguística, mídia e preconceito. 2 ed. São Paulo: Parábola Editorial, 2008.

SOARES, Magda. Linguagem e escola: uma perspectiva social. 17 ed. São Paulo: Ática, $2002(1986)$

Data de Recebimento: 26/02/2016

Data de Aprovação: 20/05/2016 


\title{
Revista do Laboratório de
}

Estudos Urbanos do Núcleo

\section{Para citar essa obra:}

Oliveira, E. V. M. A ARS (Análise de Redes Sociais): elo entre pesquisa e o ensino . In: RUA [online]. $\mathrm{n}^{\circ}$. 22. Volume 2, p. 615 - 637 - ISSN 1413-2109/2179-9911 Novembro/2016. Consultada no Portal Labeurb - Revista do Laboratório de Estudos Urbanos do Núcleo de Desenvolvimento da Criatividade.

http://www.labeurb.unicamp.br/rua/

Capa: Reproduição. Disponível em: http://keywordsuggest.org/gallery/142773.html

\author{
Laboratório de Estudos Urbanos - LABEURB \\ Núcleo de Desenvolvimento da Criatividade - NUDECRI \\ Universidade Estadual de Campinas - UNICAMP \\ http://www.labeurb.unicamp.br/ \\ Endereço: \\ LABEURB - LABORATÓRIO DE ESTUDOS URBANOS \\ UNICAMP/COCEN / NUDECRI \\ CAIXA POSTAL 6166 \\ Campinas/SP - Brasil \\ CEP 13083-892 \\ Fone/ Fax: (19) 3521-7900 \\ Contato: http://www.labeurb.unicamp.br/contato
}

